\title{
Enrolment on Health Insurance Scheme in Ghana: Evidence from Mfantseman Municipality
}

\author{
Samuel Sekyi \\ Department of Economics and Entrepreneurship Development \\ University for Development Studies, Wa Campus, Ghana \\ Email: sekyi2oo7@yahoo.com \\ Peter B. Aglobitse \\ Department of Economics, \\ University of Cape Coast, Cape Coast, Ghana \\ Email:paglobitse@gmail.com \\ and \\ Johnson Addai-Asante \\ Department of Liberal Studies and Languages \\ Kumasi Polytechnic, Kumasi, Ghana \\ Email: addaiasantejohnson@yahoo.com.ph \\ DOI//http://dx.doi.org/10.4314/gjdsv12i1\&2.4
}

\begin{abstract}
The study aimed at analysing the determinants of enrolment in the Ghana's national health insurance scheme. This survey was carried out to collect cross-sectional information from a representative sample of 384 households using a pre-tested interviewer-administered questionnaire. Multistage sampling procedure was used to select the respondents. Binary logit model was used to estimate the determinants of enrolment to the scheme. The findings show that factors such as age, occupation, place of residence, income and wealth, play an important role in shaping individuals' and households' decision to enrol. Additionally, sex, marital status, household size, and distance significantly influenced individual's decision to enrol whereas education influences household enrolment. It is recommended that appropriate educational packages be organised for the citizenry to encourage families to enrol, as the scheme prevents impoverishment resulting from catastrophic health expenditures and also improves access to healthcare. Targeted demand-side subsidy for the indigents would contribute to welfare gain and could help government achieve universal healthcare coverage.
\end{abstract}


Keywords: National Health Insurance Scheme, Determinants, Enrolment, Healthcare and Ghana

\section{INTRODUCTION}

In recent years, populations in most industrial nations enjoy universal access to a comprehensive range of health services that are financed through a combination of tax revenues, social insurance, private insurance, and charges (Preker, 1998). However, a number of low and middle-income countries such as Costa Rica, Malaysia, Sri Lanka, and Zambia have tried to follow a similar path, but the quest for financial protection against the cost of illness has been far from reality. Many of the world's 1.3 billion poor still do not have access to effective and affordable drugs, surgeries, and other interventions because of weaknesses in the financing and delivery of healthcare (ILO, 2000; WHO, 2000; World Bank, 1997). As a result, ill households in the low-income countries particularly those in the rural areas continue to use home remedies, traditional healers, and local providers who are often outside the formal healthcare system. Unfortunately, the share of the population covered by risk-sharing arrangements is relatively small. Health insurance schemes are increasingly recognised as preferable payment mechanisms to finance health care provision. Over the past several years, some African countries have established national health insurance schemes to improve access to healthcare services because it avoids direct payment and spreads the financial risk among insured members.

Financing healthcare in Ghana has gone through different transformations. Ghana's independence in 1957 brought about, among others, "free" healthcare for all Ghanaians (Ministry of Health, 2003). This meant that there was no direct out-of-pocket payment at point of consumption of healthcare. Out-of-pocket payments describe all expenses that patients have to pay to a healthcare provider according to set tariffs and directly out of their own pockets (Lasser \& Rademacher, 2006). Financing of healthcare was mainly done through tax revenue and donor support. However, with the decline in the economy in the 1960s and 1970s, sustaining "free" healthcare became a problem, hence the introduction of user fees at public health facilities in the country in 1969 (Ministry of Health, 2003).

Following the adoption of structural adjustment reforms in 1983, the government of Ghana raised and expanded user fees for public healthcare services. This became necessary because the health sector was beset with deteriorating health infrastructure, falling standards of quality care and budgetary constraints. With the objective of raising additional revenue and improving efficiency so as to prevent frivolous use of healthcare facilities, the government in 1985 increased the user fees substantially. The payment mechanism put in place was termed "Cash and Carry". Even with this system, the government meets around $80 \%$ of the cost for public healthcare while the remainder was paid by the end user at the time of use. The user fees were intended to fill the financing gap in the provision of comprehensive healthcare services. Even though the user fees system improved operating revenues for some facilities, but it was poorly regulated, 
inconsistently implemented, and was found to have worsened access to care for the poor (Agyepong \& Adjei, 2008; Assensoh \& Wahab, 2008).

Ultimately, the introduction of user fees created financial barrier to healthcare access especially among the poor leading to a decline in utilization of health services across the country. For instance, in 1985, the year in which user fees were substantially increased, outpatient visits decreased from 4.5 million to 1.6 million. In the Greater Accra region, it was found that urban healthcare utilization fell by more than $50 \%$ a year after the increase in fees (Lund, 2003). Furthermore, it was estimated that out of the $18 \%$ of the population who required healthcare at any given time, only $20 \%$ of them were able to access it (GSS, 2000). Evidence from other countries such as Kenya, Papua New Guinea, and Lesotho suggests that cost recovery policies had caused a significantly low utilization of health services especially by the poor, excluding them from access to basic healthcare (Lagarde \& Palmer, 2008; Watkins, 1997).

To cushion the burden of out-of-pocket payment for healthcare services as a result of the user fees, the government introduced an exemptions policy. The policy exempted children under the age of 5, prenatal care for pregnant women, and healthcare services for the indigent, the elderly (mainly for those above 70 years), and for disease-specific services. However, implementation problems at the district level meant that a significant number of clients who qualified for exemptions continued to face barriers in accessing basic healthcare. For example, in some hospitals, decision making was decentralized and exemptions practices were inconsistent, so that exemptions would be granted for some but not all services (Sulzbach, Garshong \& Banahene, 2005).

Recognizing the problems posed by the "Cash and Carry" system, especially its effects on healthcare utilization, the government commissioned various studies into alternative healthcare financing mechanisms, principally insurance-based ones. Initially, a lot of efforts were put into examining whether or not a National Health Insurance Scheme (NHIS) was feasible. In August 1995, the Ministry of Health received definite proposal from a private consultancy group, but this was limited to formal sector workers and registered cocoa farmers. Also, the report recommended pilot "rural-based community financed schemes" for the non-formal sector but gave no further details as to how the Ministry of Health was to do this (Aikins, 2005). An attempt to pilot the scheme in 1997 stalled for a variety of reasons (Atim, Grey \& Apoya, 2003).

However, parallel to this effort, a number of voluntary Mutual Health Organizations (MHOs) were established in response to the access obstacles created by user fees. Community-based insurance schemes were established in communities such as Nkoranza in the Brong-Ahafo Region and Dangme West in the Greater Accra Region in the early 1990 s and became models for other communities to replicate. The subsequent growth in Mutual Health Organizations (MHOs) in Ghana was noteworthy. Whereas 47 MHOs existed in 2001 (Atim \& Sock, 2000), this number tripled to 159 by 2002. By 2003, there were 168 of these schemes covering about $1 \%$ of the population (Atim et al., 2003). While these schemes have 
provided financial protection against health care costs, particularly for inpatient care for their members, the poorest households were unable to afford the contributions and so did not benefit.

Recognizing the potential of MHOs to eliminate user fees and increase utilization of healthcare, the government of Ghana passed the National Health Insurance Act 650 (HI Act) in August 2003 mandating the establishment of district-wide Mutual Health Organizations [MHOs] (GoG, 2003). As of May 2008, more than 8million people had enrolled on the district-level MHO, which covers more than $42 \%$ of the total population (Graphic Communication Group Limited, 2008).

Literature on the determinants of health insurance coverage is quite rich (see Grossman, 1972; Manning, Newhouse, Duan, Keeler \& Leibowitz, 1987; Liu, Chen \& Chen, 2002 \& Jütting, 2004). However, these studies often face the important limitation that most of them are not based on household level data and/or rely solely on qualitative methods of investigation (see for example, Arhinful, 2003; Criel \& Waelkens, 2003). Additionally, these studies usually look at the impact of schemes on the healthcare providers or the insurance scheme, largely neglecting the effects on the members. It is against this background that this study aims at filling this gap in the current body of evidence by applying quantitative method to household level data in Ghana.

\section{METHODOLOGY}

\section{Study Design}

A household survey was carried out within the Mfantseman Municipality of the Central Region of Ghana to solicit cross-sectional information from households. In all, a representative sample of 384 insured and uninsured households were selected. To select the households, the study area was divided into clusters. These clusters were constructed based on major economic activities in the area namely fishing, farming, commerce, and small scale processing activities. A town or village was selected randomly from each cluster and these constituted our target population. The selection of the number of households was based on the principle that many households were selected from communities with larger population and vice-versa. Hence, households included in the sample were selected proportionately to the total number of people in a given locality. We calculated the total number of households to be drawn from the selected towns/villages based on the 2000 Population and Housing Census figures. With the help of the Ghana Statistical Service, enumeration areas (EAs) in these communities were used. We randomly selected the EAs and listed the entire household mainly the names of household heads and their members. Thereafter, a multistage sampling procedure was used. First, a systematic sampling method was used to select households. Finally, a simple random sampling technique was used to select one household member from the sampled households. A pre- 
tested interviewer-administered questionnaire was used to collect information from the households.

\section{Methods of Data Analysis}

To estimate the determinants of enrolment on NHIS, we follow an approach applied by Weinberger and Jütting (2000). In that approach, participation in any local organization is assumed to be dependent on the rational choice of an individual weighting costs and benefits of membership. Hence, there are two options with regard to individuals' decision to participate, that is either an individual participates or otherwise. Therefore, our equation would have a binary dependent variable; hence we could use either a logit or probit model. The only difference between these two models is the underlying distributional assumption about the error term. The former assumes that the error terms follow a logistic distribution while the latter assumes that they follow a normal distribution. According to Long (1997), choosing between logit and probit models is largely one of convenience and convention, since the substantive results generated are indistinguishable. In this study, preference is given to logit model because it is easy to compute. This method is consistent with previous studies on determinants of enrolment (see for example, Jutting, 2004).

To determine the probability that an individual or a household would enrol on health insurance scheme, the functional form for the logit model can be expressed as follows:

$$
P_{i}=\frac{1}{1+e^{-\left(x_{i} \beta\right)}}
$$

Where $\mathrm{P}_{i}$ represents the probability of the $\mathrm{i}^{\text {th }}$ individual/household enrolling in the health insurance scheme; $x_{i}$ is the vector of explanatory variables and $\beta$ is the parameters to be estimated.

Then $\left(1-P_{i}\right)$ is the probability of not enrolling in health insurance scheme and is given as:

$$
1-P_{i}=\frac{1}{1+e^{\left(x_{i} \beta\right)}}
$$

Therefore, we can write

$$
\frac{P_{i}}{1-P_{i}}=\frac{1+e^{\left(x_{i} \beta\right)}}{1+e^{-\left(x_{i} \beta\right)}}=e^{\left(x_{i} \beta\right)}
$$

Now $P_{i} /\left(1-P_{i}\right)$ is simply the odds ratio in favour of enrolling in health insurance scheme.

Taken the natural log of equation (3) we obtain the log odd or logit as follows: 


$$
L_{i}=\ln \left(\frac{P_{i}}{1-P_{i}}\right)=\left(x_{i} \beta\right)
$$

In other words, from equation (3) maximizing the log-likelihood function with respect to vector $\beta$ gives the maximum likelihood estimator of $\beta$. Here, the estimated coefficients reflect the effect of a change in the independent variable upon the log of the odd ratio. This is given as:

$$
\frac{\partial}{\partial x_{i j}}\left(\log \frac{P_{i}}{1-P_{i}}\right)=\beta_{j}
$$

The marginal effects are the partial derivatives of probabilities with respect to the vector of characteristics. Hence, it measures the slope effects of the dependent variables with respect to a change in the independent variable. Generally, the marginal effects are given as follows:

$$
\frac{\partial P_{i}}{\partial x_{i j}}=P_{i}\left(1-P_{i}\right) \beta_{j}
$$

where:

$P_{i}\left(1-P_{i}\right)=$ the height of the logistic density function.

$\beta_{j}=$ the estimated coefficients of the independent variable.

In predicting the effect of changes in one of the independent variables on the probability of an individual/household enrolling on a health insurance scheme, we need to calculate these derivatives at different levels of the explanatory variables so as to realize the range of variation of the resulting changes in the probability.

Individual/household enrolment on a health insurance scheme is usually influenced by a number of factors which could be categorised into individual or household head characteristics (age, sex, education, marital status and occupation); household characteristics (household size, income and wealth); community characteristics (such as place of residence) and supply side factors (for example, distance).

\section{Measurement of Variables and a Priori Expectation}

A dummy variable was used to capture sex; here if the head of household or individual is female the value 1 is assigned and o otherwise. Females are found to consume somewhat more healthcare than their male counterparts mainly due to childbearing (Miller, 1994). Again, females are more careful about the health condition of themselves and members of their household and possibly more likely to enrol than males. Hence, we expect sex (female) variable to have a positive relation with enrolment. 
Age was taken in years. It is believed that because of other financial obligations and greater concerns about their personal health, the older a person is the more likely he/she will be risk averse. As a result we expect age to have positive correlation with enrolment.

Education was measured by the total number of years the head of household or individual spent in receiving formal education. Education plays an important role in developing a person's mind-set. Individuals with higher levels of education are typically more risk averse. This means individuals with higher education are more likely to purchase health insurance. Therefore, positive relation with enrolment on health insurance is expected for this variable.

Marital status is a dummy; here value 1 is assigned when the head of household or individual is married and o otherwise. It is argued that married individuals are wiser and more responsible towards their family members and are more likely to enrol on health insurance. Hence, marital status might have positive relationship with enrolment in health insurance.

Current occupation was captured by dummies namely farming/fishing, government sector employee, traders/business, artisan and others. Here, others became the reference category. The expected signs of these dummies are indeterminate.

Household size was defined as the number of persons residing in the same compound answerable to the same head and pooling resources of common provision like food and shelter. As household size increases demand for basic necessities of life such as food, clothing and shelter also increases thereby decreasing the household ability to purchase insurance, hence we expect this variable to have negative effect on enrolment.

Distance is a continuous variable measured in kilometres and refers to the distance (in $\mathrm{km}$ ) from the household to the nearest healthcare facility accredited by National Health Insurance Authority. The further away the household is from accredited healthcare facility the less likelihood they will enrol. We expect distance to have a negative relation with insurance enrolment.

A dummy variable was used to capture place of residence. The value 1 is assigned if the head of household or individual resides in urban area and o otherwise. It is assumed that urban residents may have better access to healthcare facility accredited by the scheme; hence, individuals residing in urban areas are more likely to enrol. Therefore, we expect this variable to have positive relation with enrolment.

Estimating household income in developing countries is often difficult as most people are reluctant to disclose their income; hence, income is generally measured by expenditure (Jütting, 2001). The approach used by Ghana Statistical Service to estimate household expenditure was adopted. The approach group household expenditure into different components namely; food and beverages, alcohol and tobacco, clothing and footwear, housing and utilities, household goods, operations and services, medical care and health 
expenses, transport and communication, recreation and education, and miscellaneous goods and services (GSS, 1992). Data on these variables was collected and the aggregates used as household expenditure. Income is a strong predictor of insurance status because as individuals' incomes rise, so do their demand for normal goods. Additionally, individuals with higher incomes are more likely to have a lower risk tolerance. We expect income to have a positive relation with enrolment in health insurance.

Wealth is measured by an asset-based wealth index, created by using key housing characteristics and household assets. Wealthy individuals or households are more likely to have a lower risk tolerance especially with regard to their health. In addition, wealthier households/individuals are more likely to demand more normal goods. Therefore, we expect the wealth variable to have positive effect on enrolment on health insurance.

\section{RESULTS AND DISCUSSION}

Table 1 and 2 show the descriptive statistics of the variables used in our estimations of determinants of enrolment at individual and household levels respectively. Of the individuals respondents $61 \%$ were female; the average age is 37 years and $60 \%$ are married. Education which was measured by the total number of years spent in receiving formal education is relatively low at a mean of 8 years. The mean household size is 4.89 and $67 \%$ of all individuals are in some form of employment (Table 1).

At household level $33 \%$ are female heads, the average age is almost 46 years, $76 \%$ are married, $76 \%$ engaged in some form of employment and the mean annual household income is GHS 2,562.10 (Table 2). 
Table 1: Descriptive statistics for variables used at individual level

\begin{tabular}{|c|c|c|c|c|c|}
\hline Variable & $\begin{array}{l}\text { Sample } \\
\text { Size }\end{array}$ & Minimum & Maximum & Mean & $\begin{array}{l}\text { Standard } \\
\text { Deviation }\end{array}$ \\
\hline \multicolumn{6}{|l|}{$\begin{array}{l}\text { Dependent variables } \\
\text { (Insurance status) }\end{array}$} \\
\hline Individual membership* & 384 & o & 1 & 0.50 & 0.501 \\
\hline \multicolumn{6}{|l|}{ Independent variables } \\
\hline Sex* & 384 & o & 1 & 0.61 & 0.489 \\
\hline Age & 384 & 18 & 88 & 37.38 & 15.382 \\
\hline Education & 384 & o & 20 & 8.44 & $5 \cdot 940$ \\
\hline Married* & 384 & $\mathrm{o}$ & 1 & 0.60 & 0.491 \\
\hline Farmer* & 384 & o & 1 & 0.13 & 0.340 \\
\hline $\begin{array}{l}\text { Government Sector } \\
\text { Employee* }\end{array}$ & 384 & o & 1 & 0.09 & 0.288 \\
\hline Trader* & 384 & o & 1 & 0.34 & 0.476 \\
\hline Artisan* & 384 & o & 1 & 0.11 & 0.316 \\
\hline Household size & 384 & 1 & 16 & 4.89 & 2.659 \\
\hline Distance & 384 & 0.20 & 3.00 & 1.3430 & 0.68295 \\
\hline Residence* & 384 & o & 1 & 0.86 & 0.345 \\
\hline Income & 384 & 360 & 8964 & 2562.1 & 1206.27 \\
\hline Wealth & 384 & 5 & 27 & 15.61 & 5.086 \\
\hline
\end{tabular}

* = categorical indicator variable

Source: Field Work, August 2008 
Samuel Sekyi, Peter B. Aglobitse \& Johnson Addai-Asante

Enrolment on Health Insurance Scheme in Ghana: Evidence from Mfantseman Municipality

Table 2: Descriptive statistics for variables used at household level

\begin{tabular}{|c|c|c|c|c|c|}
\hline Variable & $\begin{array}{l}\text { Sample } \\
\text { Size }\end{array}$ & Minimum & Maximum & Mean & $\begin{array}{l}\text { Standard } \\
\text { Deviation }\end{array}$ \\
\hline \multicolumn{6}{|l|}{$\begin{array}{l}\text { Dependent variables } \\
\text { (Insurance status) }\end{array}$} \\
\hline Household membership* & 384 & o & 1 & 0.43 & 0.495 \\
\hline \multicolumn{6}{|l|}{ Independent variables } \\
\hline Sex ${ }^{*}$ & 384 & o & 1 & 0.33 & 0.471 \\
\hline Age & 384 & 23 & 88 & 45.80 & 14.456 \\
\hline Education & 384 & o & 20 & 8.96 & 5.826 \\
\hline Married* & 384 & o & 1 & 0.76 & 0.427 \\
\hline Farmer* & 384 & o & 1 & 0.16 & 0.371 \\
\hline $\begin{array}{l}\text { Government Sector } \\
\text { Employee* }\end{array}$ & 384 & o & 1 & 0.11 & 0.319 \\
\hline Trader* & 384 & $\mathrm{o}$ & 1 & 0.35 & 0.478 \\
\hline Artisan* & 384 & o & 1 & 0.14 & 0.351 \\
\hline Household size & 384 & 1 & 16 & 4.89 & 2.659 \\
\hline Distance & 384 & 0.20 & 3.00 & 1.3430 & 0.68295 \\
\hline Residence* & 384 & $\mathrm{o}$ & 1 & 0.86 & 0.345 \\
\hline Income & 384 & 360 & 8964 & $2,562.1$ & 1206.27 \\
\hline Wealth & 384 & 5 & 27 & 15.61 & 5.086 \\
\hline
\end{tabular}

* = categorical indicator variable

Source: Field Work, August 2008

Table 3 presents the results of logit estimation reporting both coefficients and marginal effects of the determinants of enrolment in health insurance scheme at individual and household levels. The two models fit the data reasonably well mainly because about $74.74 \%$ of the enrolment outcomes are correctly predicted and the likelihood-ratio (LR) test of the hypothesis that all regression coefficients are jointly equal to zero is emphatically rejected. Overall, significant relationships are observed between the probabilities of the dependent variables and the set of explanatory variables included in the models. 
Table 3: Logit result on determinants of enrolment in health insurance

\begin{tabular}{|c|c|c|c|c|}
\hline \multicolumn{3}{|c|}{ Individual level } & \multicolumn{2}{|c|}{ Household level } \\
\hline Variables & Coefficient & Marginal Effect & Coefficient & Marginal Effect \\
\hline Sex & $\begin{array}{l}0.8816354^{* * *} \\
(0.2892352) \\
\end{array}$ & $\begin{array}{l}0.2169039 \\
(0.0688)\end{array}$ & $\begin{array}{l}0.3383087 \\
(0.3310043)\end{array}$ & $\begin{array}{l}0.0814769 \\
(0.07846) \\
\end{array}$ \\
\hline Age & $\begin{array}{l}0.0277106^{* * *} \\
(0.0087406)\end{array}$ & $\begin{array}{l}0.0069086 \\
(0.00218)\end{array}$ & $\begin{array}{l}0.0272151^{* * *} \\
(0.0092455)\end{array}$ & $\begin{array}{l}0.0066334 \\
(0.00225)\end{array}$ \\
\hline Education & $\begin{array}{l}0.0307771 \\
(0.0277078)\end{array}$ & $\begin{array}{l}0.0076731 \\
(0.00691)\end{array}$ & $\begin{array}{l}0.2089962^{*} \\
(0.1107405)\end{array}$ & $\begin{array}{l}0.050941 \\
(0.02706)\end{array}$ \\
\hline Married & $0.5518898^{*}(.2885424)$ & $\begin{array}{l}0.1370133 \\
(0.07085)\end{array}$ & $\begin{array}{l}-0.16284 \\
(0.3597869) \\
\end{array}$ & $\begin{array}{l}-0.0399197 \\
(0.08863)\end{array}$ \\
\hline Farmer & $\begin{array}{l}-0.3659558 \\
(0.4328487) \\
\end{array}$ & $\begin{array}{l}-0.091215 \\
(0.10707) \\
\end{array}$ & $\begin{array}{l}-0.9871842^{* *} \\
(0.4178475)\end{array}$ & $\begin{array}{l}-0.2192666 \\
(0.08059)\end{array}$ \\
\hline $\begin{array}{l}\text { Government } \\
\text { Sector } \\
\text { Employee }\end{array}$ & $\begin{array}{l}1.884538^{* * * *} \\
(0.7159814)\end{array}$ & $\begin{array}{l}0.3769832 \\
(0.09138)\end{array}$ & $\begin{array}{l}1.230706^{* *} \\
(0.5861764)\end{array}$ & $\begin{array}{l}0.2966908 \\
(0.12767)\end{array}$ \\
\hline Trader & $-0.2221169(0.337412)$ & $\begin{array}{l}-0.055404 \\
(0.08409)\end{array}$ & $\begin{array}{l}-0.3619276 \\
(0.3291959) \\
\end{array}$ & $\begin{array}{l}-0.0871951 \\
(0.0782) \\
\end{array}$ \\
\hline Artisan & $\begin{array}{l}-0.9864049^{* *} \\
(0.4397944)\end{array}$ & $\begin{array}{l}-0.237383 \\
(0.09679)\end{array}$ & $\begin{array}{l}-1.423772^{* * * *} \\
(0.4526857) \\
\end{array}$ & $\begin{array}{l}-0.294547 \\
(0.07254) \\
\end{array}$ \\
\hline Household size & $\begin{array}{l}-0.0885966^{*} \\
(0.0518439)\end{array}$ & $\begin{array}{l}-0.0220882 \\
(0.01293)\end{array}$ & $\begin{array}{l}-0.0305988 \\
(0.05239)\end{array}$ & $\begin{array}{l}-0.0074582 \\
(0.01276)\end{array}$ \\
\hline Distance & $\begin{array}{l}-0.7248828^{* *} \\
(0.3480591)\end{array}$ & $\begin{array}{l}-0.1807221 \\
(0.08675) \\
\end{array}$ & $\begin{array}{l}-0.4989703 \\
(0.3664829) \\
\end{array}$ & $\begin{array}{l}-0.1216197 \\
(0.08934)\end{array}$ \\
\hline Residence & $\begin{array}{l}-1.624764^{* *} \\
(0.6786035) \\
\end{array}$ & $\begin{array}{l}-0.3481719 \\
(0.11075) \\
\end{array}$ & $\begin{array}{l}-1.174415^{*} \\
(0.7111831) \\
\end{array}$ & $\begin{array}{l}-0.2847131 \\
(0.15947) \\
\end{array}$ \\
\hline Income & $\begin{array}{l}0.000555^{4 * *} \\
(0.0001338) \\
\end{array}$ & $\begin{array}{l}0.0001384 \\
(0.00003)\end{array}$ & $\begin{array}{l}0.0003736^{* * *} \\
(0.0001185)\end{array}$ & $\begin{array}{l}0.0000911 \\
(0.00003)\end{array}$ \\
\hline Wealth & $\begin{array}{l}0.1336857^{* * *} \\
(0.0319111)\end{array}$ & $\begin{array}{l}0.0333295 \\
(0.00795)\end{array}$ & $\begin{array}{l}0.0952794^{* * *} \\
(0.0302066)\end{array}$ & $\begin{array}{l}0.0232235 \\
(0.00735)\end{array}$ \\
\hline Constant & $-1.812757(1.178575)$ & & $\begin{array}{l}-2.363741^{*} \\
(1.283201)\end{array}$ & \\
\hline $\begin{array}{l}\text { Number of obse } \\
\text { Log likelihood- } \\
\text { LR chi2(13) } 140 . \\
\text { Prob > chi2 } 0.00 \\
\text { Pseudo R2 } 0.264 \\
\text { Model classifica }\end{array}$ & $\begin{array}{l}\text { vations } 384384 \\
95.83021-197.93648 \\
\text { B } 128.27 \\
\text { o } 0.0000 \\
\text { o. } 2447 \\
\text { on } 74.74 \% 74.74 \%\end{array}$ & & & \\
\hline
\end{tabular}

Source: Field Work, August 2008

Note: ${ }^{* * *}$ Significance at $1 \%{ }^{* *}$, Significance at $5 \%$ and Significance at $10 \%$ 
The result reveals that probability of individual enrolling on the scheme is influenced to a great extent by sex, age, marital status, government worker and artisan occupations, household size, distance, place of residence, income and wealth. All these variables showed signs that are in tandem with theoretical expectations, with the exception of residence.

As stated earlier, the sex (female) variable had the expected sign. A positive sign indicates that females are more likely to enrol than their male counterparts. This finding can probably be attributed to the fact that as the main health caregivers in the family, females are more likely to internalize the costs and consequences associated with healthcare than men. Hence, often they take precautionary measures to reduce the cost by enrolling on health insurance scheme. This strong positive effect of the sex (female) dummy on enrolment supports earlier findings by Munkin and Trivedi (2003) and Sulzbach et al. (2005) which revealed that females are more likely to be insured.

Age has a positive relation with enrolment and is highly significant. This suggests that age does have an effect on an individual's mindset. As a person becomes older, he/she tends to become more conservative, preferring a fixed level of utility. Alternatively, economic theory postulates that as individuals advance in age, their inherited health stock depreciates at an increasing rate thus inducing increased investments in health (including taking health insurance policy) in an attempt to decrease the rate of depreciation. Grossman (1972) observed that because the health stock depreciation rate rises with age, it is most likely that unhealthy (old) people will make larger gross investments in health than healthy (young) people. This result is consistent with evidence emerging from the literature, including U.S. Census Bureau (2002), Munkin and Trivedi (2003) and Sulzbach et al. (2005).

Marital status has a weak statistical significance with enrolment on health insurance; however, it has the expected positive sign. This finding suggests that, for instance, if unmarried individuals were to get married their probability of demanding health insurance will increase by 13.7 percentage points. This finding can probably be attributed to the fact that married couples tend to be more averse to the risk of devastating health expenditures (Harmon \& Nolan, 2001). Similar findings were reported by Liu et al. (2002) and Munkin and Trivedi (2003).

With regard to household size, it has the expected negative effect on enrolment on health insurance scheme. At $10 \%$ level of significance, it is accepted that the decision to enrol is marginally influenced by household size. Intuitively, this result makes sense since any increase in the household size, holding household income constant, reduces the per capita income, hence decreasing an individual's likelihood of enrolling on the scheme. This result is in agreement with Diop, Sulzbach and Chankova (2006), Jütting (2004), Kirigia, Sambo and Mwase (2005) who reported a negative significant relationship between participation in health insurance and household size. 
Four occupation dummies have been explored to investigate their empirical significance in terms of health insurance enrolment. The reference category was "other" occupation. Two of the four dummy variables; namely government sector employee and artisan are statistically significant. For instance, if individuals in "other" occupation were to be employed in the government sector their probability of enrolling in the health insurance scheme will increase by 37.7 percentage points. This is not surprising since all contributors to Social Security and National Insurance Trust are under compulsion to register as members of the NHIS, and do not incur so much cost in terms of out-of-pocket payment.

A supply side variable, that is, "distance to nearest health facility" which is often scarcely accounted for in most studies on health insurance has the correct sign and is statistically significant at $5 \%$ level. This result indicates that access or proximity to healthcare facility will induce enrolment. One of the few studies that catered for this variable, NketiahAmponsah (2009), also found a significant statistical relationship between distance to nearest health facility and health insurance participation.

The coefficient of the residence variable did not have the expected sign. The result suggests that the probability of urban residence not enrolling on the scheme is 34.8 percentage points. Plausible explanation for this finding is the fact that urban residence could afford to make out-of-pocket payment for healthcare services. This result is consistent with findings from Jehu-Appiah, Aryeetey and Spaan (2011), Sarpong, Loag, Fobil, Meyer, Adu-Sarkodie, May and Schwarz (2010), Stock (1983), and Bennet, Creese and Monasch (1998) who observed that residential remoteness plays an important role in insurance enrolment.

Income has a strong positive impact on the probability of being a member of the scheme. This is statistically significant at the $1 \%$ level. This implies that individuals with higher incomes are much more likely to enrol themselves than individuals with lower incomes. Economic theory stipulates a positive relationship between demand for normal goods and income. Therefore, as people's incomes rise they are more likely to purchase normal goods including health insurance. This result reinforces studies by Temple (2002), Munkin and Trivedi (2003), and Makoka, Kaluwa and Kambewa (2007).

Wealth has a positive relation with enrolment and is highly significant. The marginal effect suggests that a 1\% increase in household wealth increases the probability of enrolment in health insurance by 3.3\%. This means that individuals from wealthy households are more likely to enrol. This result confirms Jütting's (2002) study.

To determine enrolment at the household level, the insurance status of the household head was used as a proxy for whether or not a household is enrolled on NHIS. At the household level, eight variables are significant namely, age, education, farmer, government worker and artisan occupations, place of residence, income and wealth. Here too all the variables had the expected sign with the exception of the residence variable. 
At the household level just like the situation at individual level, age has a strong positive impact on the probability of being a member of the scheme. This result supports the earlier assertion that age does have a positive effect on a person's mind-set. Therefore, as the head of household becomes older, they tend to become more conservative, preferring a fixed level of utility such as insurance policy.

Education has a significantly positive effect on health insurance enrolment. The positive sign indicates that there is a direct relationship between education and enrolment. The marginal effect of education suggests that the probability of enrolment would increase by $5 \%$ for every additional year of education of the head of household. Plausible explanation for this finding is that education increases the knowledge of the household head about the benefits associated with health insurance membership. This result is consistent with earlier studies such as Sulzbach et al. (2005) and Diop et al. (2006) which reveal that the higher the level of education of heads of household, the more likely they are to enrol than heads of household with lower education.

Of the four occupational dummies three were statistically significant namely farming, government sector employee and artisan. For instance, if heads of household in the reference category that is "other" occupation were to engage in farming, their probability of enrolling on the health insurance scheme will decrease by 22 percentage points.

Residence of household heads negatively affects their decision to enrol on the scheme. This has a weak statistical significance at the $10 \%$ level. The result suggests that the probability of urban residence enrolling on the scheme would decrease by 28 percentage points.

At the household level, just like the individual level, income has a strong positive effect on the probability of being a member of the scheme. This indicates that ability to pay does make a difference in the decision to join the scheme as households with higher income are more likely to join the scheme than households with lower income. This finding can probably be attributed to the fact that increased income increases the affordability of health insurance premiums by the household.

The coefficient of the wealth variable has the hypothesized sign and is statistically significant. The result suggests that a $1 \%$ increase in household wealth would increase probability of enrolment by 2.3 percentage points.

\section{CONCLUSION}

This study sought to analyse the determinants of enrolment on Ghana's National Health Insurance Scheme. A survey was carried out to solicit cross-sectional information from a representative sample of 384 households using a pre-tested interviewer-administered questionnaire. Logit model was used to estimate the determinants of enrolment at both individual and household levels. The results drawn from the logit models concluded that 
individuals' decision to enrol on the scheme is significantly influenced by sex, age, marital status, government worker and artisan occupations, household size, distance, place of residence, income and wealth. Additionally, the probability of household enrolling on the scheme is significantly determined by age, education, farmer, government worker and artisan occupations, place of residence, income and wealth.

A number of policy suggestions can be extrapolated from this study. First, recognising the importance of education in determining enrolment, we recommend that appropriate educational packages both, formal and informal, should be organised for the citizenry. Public education should be embarked upon to encourage families to enrol, as the scheme has immediate direct and indirect impact on poverty. The direct impact would be by preventing impoverishment resulting from catastrophic health expenditures while the indirect impact would be by ensuring access to health and thereby improving health status, thus allowing the individual to take advantage of economic and social opportunities. In furtherance of these, the Public Relation Officers of the various schemes at the districts should intensify their educational and sensitization programmes especially in the urban areas.

Lastly, the results suggest that there is consistent evidence of association between economic status as indicated by income and wealth of individual/household and the likelihood of enrolment. It must be noted that participation in health insurance schemes is not cost-free and requires a minimum level of income which the most disadvantaged often do not have at their disposal. Therefore, in order to reach the poorest members of the society, the cost of enrolment, that is premiums would have to be subsidized. This targeted demand-side subsidy would contribute to welfare gain if they reach the indigents and would help government achieve universal healthcare coverage. Even though the Act that established the NHIS in Ghana made provision for the indigents or the very poor to be exempted from paying premium, it has become increasingly difficult, if not impossible, to identify them. Chiefs, opinion leaders, assemblymen or assemblywomen and other concerned citizens in the communities should help in identifying the very poor so that they could be exempted from paying premium.

\section{References}

Agyepong, I. A. and Adjei, S. (2008). Public social policy development and implementation: A case study of the Ghana national health insurance scheme. Health Policy Plan, 23, pp. 150-16o.

Aikins, M. (2005). Jaman South Health Insurance Scheme Brong Ahafo Region, External Evaluation, 2004. Accra: Uneek Magazine Publication.

Arhinful, D. (2003). The solidarity of self-interest: social and cultural feasibility of rural health insurance in Ghana. Leiden, Netherlands: African Studies Centre. Research report 71. 
Assensoh, A. B. and Wahab, H. (2008). A historical-cumpolitical overview of Ghana's national health insurance law. African and Asian Studies; 7(2/3), pp. 289-306.

Atim, C. (1998). Contribution of mutual health organizations to financing delivery and access to health care: Synthesis of research in nine West and Central African Countries. Bethesda, MD: Partners for Health Reformplus, Abt Associates Inc.

Atim, C., Grey, S. and Apoya, P. (2003). A survey of mutual health organizations in Ghana. Bethesda, MD: Partners for Health Reformplus, Abt Associates Inc.

Atim, C. and Sock, M. (2000). An external evaluation of the Nkoranza community financing health insurance scheme, Ghana. Bethesda, MD: Partners for Health Reformplus, Abt Associates Inc.

Bennet, S., Creese, A. and Monasch, R. (1998). Health insurance schemes for people outside formal sector employment: Current concerns. World Health Organization ARA Paper Number 16, Geneva.

Criel, B. and Waelkens, M. P. (2003). Declining subscriptions to the Maliando mutual health organization in Guinea-Conakry (West Africa): what is going wrong? Social Science and Medicine 57, pp. 1205-19.

Diop, F. P., Sulzbach, S. and Chankova, S. (2006). The impact of mutual health organizations on social inclusion, access to health care, and household income protection: Evidence from Ghana, Senegal, and Mali. Bethesda, MD: The Partners for Health Reformplus Project, Abt Associates Inc.

Ghana Statistical Service. (1992). Ghana Living Standard Survey, GLSS2. Accra: Ghana Statistical Service.

Ghana Statistical Service. (2000). Ghana Living Standard Survey, GLSS4. Accra: Ghana Statistical Service.

Government of Ghana. (2003). The National Health Insurance Act: Act 650. Accra: Ghana Government.

Graphic Communication Group Limited. (2008, May 7). NHIS coverage rate exceeded targets-CEO. Daily Graphic, pp.15.

Grossman, M. (1972). On the concept of health capital and the demand for health. Journal of Political Economy, 8o, pp. 223-255.

Harmon, C. and Nolan, B. (2001). "Health insurance and health service utilization in Ireland". Health Economics, 10, pp. 135-145.

International Labour Organisation. (2000). Mutuelles de santé en Afrique: Charactéristiques et mise en place. Manuel de formateurs. Programme Stratégies et Technique contre l'Exclusion sociale et la Pauvreté, Département de Sécurité Sociale (STEP). Geneva. 
Jehu-Appiah, C., Aryeetey, G. C. and Spaan, E. (2011). Who is enrolling, who is not and why? An assessment of equity of the national health insurance in Ghana. Social Science \& Medicine, 72, pp. 157-162.

Jütting, J. (2001). The impact of health insurance on the access to health care and financial protection in rural areas of developing countries: The example of Senegal (online). Available at: http://www.zef.de. Accessed: $22^{\text {nd }}$ September 2007.

Jütting, J. (2002). The impact of community-based health financing on financial protection: Case study Senegal. HNP Discussion Paper, World Bank. Washington, D.C.: World Bank.

Jütting, J. (2004). Do community-based health insurance schemes improve poor people's access to health care? Evidence from rural Senegal. World Development 32, pp. 27388.

Kirigia, J. M., Sambo, L. G. and Mwase, T. (2005). Determinants of health insurance ownership among South African women. BMC Health Services Research, 5(17).

Lagarde, M. and Palmer, N. (2008). The impact of user fees on health service utilization in low - and middle-income countries: how strong is the evidence? Bulletin of the World Health Organization, 86, pp. 839-848.

Lasser, U. and Rademacher R. (2006). Financing health care: A dialogue between South Eastern Europe and Germany. International Public Health, Vol. 18, pp.9-23.

Liu, T. C., Chen, C. S. and Chen, L. M. (2002). The impact of national health insurance on neonatal care use and childhood vaccination in Taiwan. Health Policy and Planning, $17(4), p p \cdot 384-392$.

Long, J. S. (1997). Regression models for categorical and limited dependent variables. London: Sage Publications.

Lund, s. (2003). Health insurance schemes in northern Ghana: A case study of Salamba women's health insurance scheme. Accra: Chaiglo Print Services.

Makoka, D., Kaluwa, B. and Kambewa, P. (2007). Demand for private health insurance where public health services are free: The case of Malawi. Journal of Applied Sciences, 21, pp. 3268-3273.

Manning, W., Newhouse, J., Duan, N., Keeler, E., Leibowitz, A. and Marquis, M. (1987). Health insurance and the demand for medical care: Evidence from a randomised experiment. American Economic Review, 77, pp. 251-277.

Miller, L. (1994, May 24). Medical schools put women in curricula. Wall Street Journal, p. B1.

Ministry of Health. (2003). National health insurance policy framework for Ghana. Accra: Ministry of Health. 
Munkin, M. K. and Trivedi, P. K. (2003). Bayesian analysis of a self-selection model with multiple outcomes using simulation-based estimation: An application to the demand for healthcare. Journal of Econometrics, pp. 197-220.

Nketiah-Amponsah, E. (2009). Demand for Health insurance among women in Ghana: Cross sectional evidence. International Research Journal of Finance and Economics, Issue 33 .

Preker, A. S. (1998). The introduction of universal access to health care in the OECD: lessons for developing countries. In S. Nitayarumphong and A. Mills, (eds.), Achieving universal coverage of health care. Bangkok: Ministry of Public Health.

Sarpong, N., Loag W., Fobil, J., Meyer, C. G, Adu-Sarkodie Y., May, J. and Schwarz, N. G. (2010). National health insurance coverage and socio-economic status in a rural district of Ghana. Tropical Medicine and International Health, 15, pp. 191-197.

Stock, R. (1983). Distance and utilization of health facilities in rural Nigeria. Social Science and Medicine, 17, pp. 63-570.

Sulzbach, S., Garshong, B. and Banahene, G. (2005). Evaluating the effects of the national health insurance act in Ghana: Baseline report. Bethesda, MD: The Partners for Health Reformplus Project, Abt Associates Inc.

Temple, J. (2002). Explaining the private health insurance coverage of older Australians. People and Place, 12(2), pp. 13-23.

U.S. Census Bureau. (2002). Health insurance coverage in the United State, (online). Available at: http://www.census.gov/prod/2003pubs/p6o-223. Accessed: $28^{\text {th }}$ January, 2008.

Watkins, K. (1997). Cost recovery and equity in the health sector: Issues for developing countries. Paper prepared for WIDEW project on provision and financing of public goods in developing countries. Oxfam: United Kingdom and Ireland policy department.

Weinberger, K. and Jütting, J. (2000). The role of local organizations in risk management: Some evidence from rural Chad. Quarterly Journal of International Agriculture, 39 (3), pp. 281-299.

World Health Organization. (2000). World Health Report 2000: Health SystemsMeasuring Performance. Geneva.

World Bank. (1997). Sector strategy for HNP. Washington, D.C.

World Health Organization. (2000). Health for all policy for the 21st century in the African region: Agenda 2020. AFR/RC50/8.Rev. ICIA. 